\title{
Performance Analysis of SOFC with Electrode-electrolyte Interface Tailored by Laser Micro-machining
}

\author{
Taishi Nakagawa ${ }^{\mathrm{a}}$, Masashi Kishimoto ${ }^{\mathrm{a}}$, Hiroshi Iwai ${ }^{\mathrm{a}}$, Motohiro Saito ${ }^{\mathrm{a}}$, Hideo Yoshida ${ }^{\mathrm{a}}$, \\ Ruth Lahoz ${ }^{\mathrm{b}}$, Miguel A. Laguna-Bercero ${ }^{\mathrm{c}}$, Ángel Larrea ${ }^{\mathrm{c}}$ \\ ${ }^{a}$ Department of Aeronautics and Astronautics, Kyoto University, Kyoto 615-8540, Japan

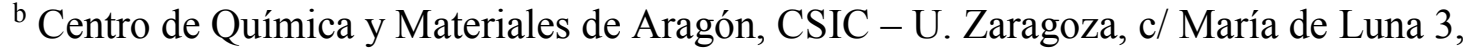 \\ E-50.018 Zaragoza, Spain \\ ${ }^{\mathrm{c}}$ Instituto de Ciencia de Materiales de Aragón, CSIC - U. Zaragoza, c/ María de Luna 3, \\ E-50.018 Zaragoza, Spain
}

\begin{abstract}
The interfacial area between the electrode and the electrolyte of solid oxide fuel cells (SOFCs) is increased by a pulsed-laser machining to expand the active electrochemical reaction region. The pulsed-laser machining is performed on the surface of the YSZ flat electrolytes to fabricate micro-patterned craters. The surface profiles of the patterned electrolytes are measured by a 3D laser profiler. Then, LSM cathode is fabricated on the laser-machined surface of the YSZ electrolyte, while Ni-YSZ anode on the flat side. The performance of the fabricated cell with the patterned interface is experimentally evaluated at $900^{\circ} \mathrm{C}$ and compared with that of the conventional cell having the flat interface. $3 \mathrm{D}$ numerical simulations are also performed on the patterned cell to understand the distributions of the activation overpotentials and the charge-transfer current at the interface. A power density enhancement is confirmed in the cell with the patterned interface in both experiment and simulation.
\end{abstract}

\section{Introduction}

Electrochemical reactions in solid oxide fuel cell (SOFC) occur at the triple-phase boundaries (TPBs) and double-phase boundaries (DPBs) as the reaction sites in the porous electrodes. Therefore, increasing the volumetric density of these reaction sites is the common approach to improve the electrode performance (1-3). On the other hand, increasing the electrode-electrolyte interfacial area in mesoscale $(10-100 \mu \mathrm{m})$ by fabricating micro-patterns is also effective (4-8) because the electrochemical reaction mainly occurs in the vicinity of the electrode-electrolyte interface with a thickness around $10-20 \mu \mathrm{m}$.

Several works reported improvement of the performance in the cells having micropatterns on the electrode-electrolyte interfaces. Konno et al. (4) and Iwai et al. (7) employed the sand-blasting technique to fabricate meso-scale $(10-100 \mu \mathrm{m})$ patterns on the interface and confirmed performance improvement both by experiment and numerical simulation. Cebollero et al (9) used the pulse-laser machining to apply periodic and uneven structure on the cathode-electrolyte interface and reported that the activation resistance was decreased by $30 \%$ compared with the standard cell having the flat interface. 
Although the performance improvement by adding meso-scale patterns on the electrode-electrolyte interface has been reported experimentally, the mechanism of the improvement has not been explored in detail. Therefore, in this study, 3D numerical simulation is conducted in an electrolyte-supported button cell having a patterned interface to understand the origin of the performance improvement.

\section{Experimental}

\section{The Pulsed-laser Machining of the YSZ Electrolytes}

A pulse laser apparatus (Powerline S3 SHG, Rofin, Germany) was used to process the surface of flat YSZ electrolytes (Tosoh Corp., Japan) with a diameter of $24 \mathrm{~mm}$ and thickness of $500 \mu \mathrm{m}$. The pulse laser is a commercial Q-switched diode-pumped laser with a wavelength of $532 \mathrm{~nm}$ and a minimum pulse interval of $5 \mathrm{~ns}$. The average power of the laser is $2 \mathrm{~W}$, and a pulse frequency range is $15-400 \mathrm{kHz}$. This is also equipped with a galvanometric mirror to scan the surface of a sample by deflecting the laser beam. More details can be found elsewhere (9).

Figure 1 shows the schematic image of the laser patterning in this study. One side of the electrolyte was processed by the laser machining to make a hexagonal pattern on the YSZ surface. The conditions of the laser machining are shown in TABLE I. The distance between the neighboring patterns were set as $22 \mu \mathrm{m}$.

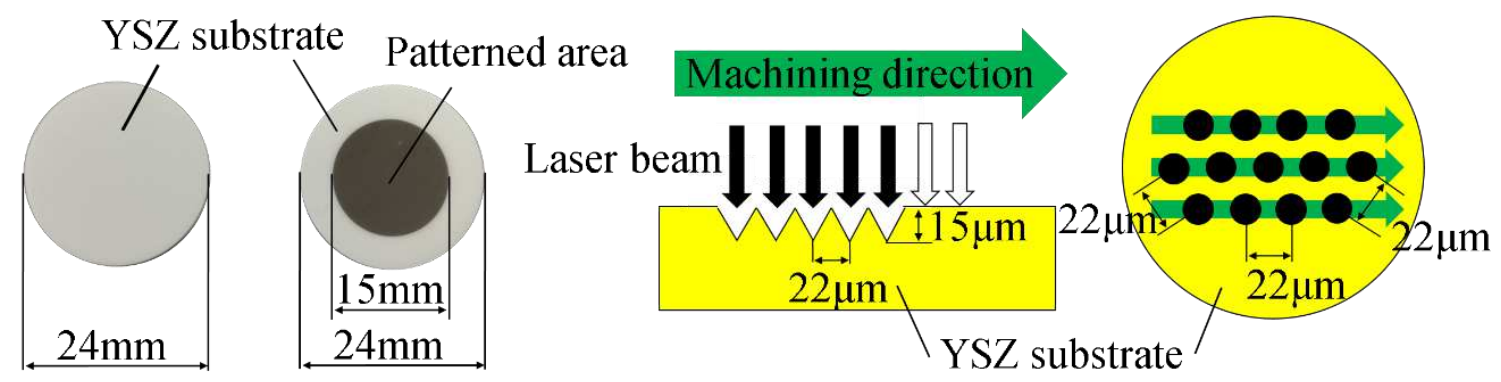

Figure 1. Schematic image of the laser patterning on the YSZ electrolyte.

TABLE I. Laser conditions.

\begin{tabular}{lc}
\hline Parameter & Value \\
\hline Current $[\mathrm{A}]$ & 7.5 \\
Frequency $[\mathrm{Hz}]$ & 15000 \\
Scan speed $[\mathrm{mm} / \mathrm{s}]$ & 150 \\
The number of repetitions [pulses] & 6 \\
\hline
\end{tabular}


Measurement of the Surface Profile of the Patterned Electrolytes

The surface morphology of the patterned YSZ electrolyte was analyzed using a 3D laser confocal microscope (LEXT OLS4000, Olympus, Japan). The surface profile was measured at $1024 \times 1024$ positions with $0.25 \mu \mathrm{m}$ resolution. Since the surface morphology obtained by the laser machining has a periodic hexagonal structure, a repeating unit was identified from the image and the average surface profile of the repeating units was evaluated; the calculation domain of the numerical simulation described below will be conducted only in the representative repeating unit to decrease the computational load. The averaging procedures is as follows. First, a set of vectors $\vec{a}$ and $\vec{b}$, which determines the distance and orientation of the neighboring repeating units, is assumed on the basis of the design parameters during the laser machining, and the dataset was divided into several repeating units. About 160 repeating units were identified in this study. Then, the surface profile was averaged among all the repeating units and its standard deviation was also obtained. As the obtained hexagonal pattern slightly was not completely the same as that from the designed pattern, the vectors $\vec{a}$ and $\vec{b}$ were adjusted so that the standard deviation was minimized. Then, the averaged surface profile was resampled to have a grid size of $0.5 \mu \mathrm{m}$ to make a grid system for the numerical simulation.

\section{Fabrication of Button Cells and Electrochemical Measurements}

First, a Ni-YSZ anode was fabricated on the flat side of the electrolyte. A mixture powder of $\mathrm{NiO}-\mathrm{YSZ}(\mathrm{Ni}: \mathrm{YSZ}=50: 50 \mathrm{vol} \%)$ was prepared using a planetary ball-mill and mixed with terpineol-based binder (VEH, Nexceris, LLC, U.S.A.) to form a slurry. The anode slurry was screen printed on the YSZ disk using a metal mask with $60 \mu \mathrm{m}$ in thickness and $10 \mathrm{~mm}$ in diameter, and then sintered at $1400^{\circ} \mathrm{C}$ for $5 \mathrm{~h}$. The LSM cathode was then printed on the patterned side of the electrolyte. The LSM paste was fabricated by mixing the commercial LSM powder (LSM-I, Nexceris, LLC, U.S.A.) and the same binder as used for the anode paste. The cathode slurry was screen printed on the YSZ disk using the same mask as used for the anode and sintered at $1150^{\circ} \mathrm{C}$ for $5 \mathrm{~h}$. Platinum wire was attached around the side edge of the YSZ electrolyte and used as a reference electrode for electrochemical measurement. The flat YSZ electrolyte with the same anode and cathode was also used as a reference cell. A cell with the flat interfaces on both sides was also fabricated with the same procedure.

The electrochemical performance of the cells was evaluated using an SOFC button cell evaluation system (BEL-SOFC, MicrotracBEL Inc., Japan). The cells were held with alumina tubes and their temperature was controlled by an electric furnace. The supplied gas compositions were controlled by mass flow controllers and the humidity of the fuel was controlled by a bubbler. In this study, the supplied gas on the anode side was $20 \%$ humidified hydrogen at $100 \mathrm{sccm}$, whereas that on the cathode side was the synthetic dry air at $100 \mathrm{sccm}$. The furnace temperature was kept at $900^{\circ} \mathrm{C}$. The electrochemical measurements were performed with a four-terminal method; current-voltage characteristics was measured from the open-circuit potential to the terminal voltage of $0.3 \mathrm{~V}$ with $5 \mathrm{mV}$ increment, and the electrochemical impedance spectroscopy was obtained in a frequency range of $10^{6}$ to $10^{-1} \mathrm{~Hz}$ with an current amplitude of $10 \mathrm{~mA}$. 


\section{Numerical Modeling}

\section{Calculation Domain}

Figure 2 shows the schematic image of the calculation domains in this study. The electrolyte-supported SOFC cells consisting of porous a Ni-YSZ anode, a dense YSZ electrolyte and a porous LSM cathode were considered. The $Z$ axis corresponds to the thickness of the cell, whereas the X-Y plane was in parallel to the electrode-electrolyte interface. The averaged surface profile was implemented to the cathode-electrolyte interface. The microstructural parameters for the anode and cathode obtained by FIB-SEM analysis in (10) were used and shown in TABLE II. The anode and cathode thicknesses were kept constant at $30 \mu \mathrm{m}$, whereas the electrolyte thickness was varied. It should be noted that the average cathode and electrolyte thickness were slightly altered in the patterned cell.

TABLE II summarizes the geometries used in the numerical analysis. The electrode thickness was varied as 100, 300 and $500 \mu \mathrm{m}$. Also, the averaged shape of the cathodeelectrolyte interface was virtually expanded by two and three times to investigate the effect of the crater depth.

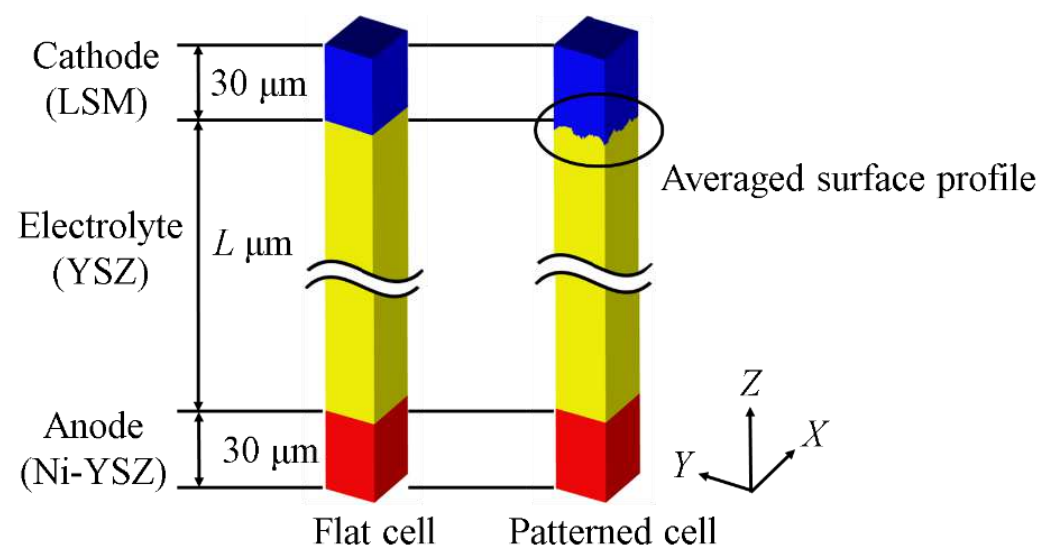

Figure 2. Schematic image of the calculation domains.

TABLE II. Microstructural parameters of the electrodes.

\begin{tabular}{|c|c|c|c|c|c|}
\hline \multirow{2}{*}{ Parameters } & \multicolumn{2}{|c|}{ Cathode } & \multicolumn{3}{|c|}{ Anode } \\
\hline & LSM & Pore & $\mathrm{Ni}$ & YSZ & Pore \\
\hline Volume fraction [-] & 0.643 & 0.357 & 0.287 & 0.439 & 0.274 \\
\hline Tortuosity [-] & 1.43 & 2.22 & 5.89 & 2.04 & 12.3 \\
\hline TPB density & \multicolumn{2}{|c|}{$1.55\left[\mu^{-1}\right]$} & \multicolumn{3}{|c|}{$2.95\left[{\left.\mu \mathrm{m}^{-2}\right]}\right.$} \\
\hline $\begin{array}{l}\text { Ratio of surface area to } \\
\text { volume in pore phase }\left[\mu^{-1}\right]\end{array}$ & \multicolumn{2}{|c|}{1.95} & \multicolumn{3}{|c|}{6.48} \\
\hline
\end{tabular}

TABLE III. Geometries of the calculation domain.

\begin{tabular}{ccc}
\hline Name & Thickness of electrolyte $[\mu \mathrm{m}]$ & Cathode-electrolyte interface \\
\hline $100 \mathrm{~F}$ & 100 & Flat \\
$300 \mathrm{~F}$ & 300 & Flat \\
$500 \mathrm{~F}$ & 500 & Flat \\
$100 \mathrm{P} 1$ & 100 & Averaged surface profile $\mathrm{x} 1$
\end{tabular}




$\begin{array}{lll}300 \mathrm{P} 1 & 300 & \text { Averaged surface profile x 1 } \\ 500 \mathrm{P} 1 & 500 & \text { Averaged surface profile } \mathrm{x} 1 \\ 500 \mathrm{P} 2 & 500 & \text { Averaged surface profile x 2 } \\ 500 \mathrm{P} 3 & 500 & \text { Averaged surface profile x 3 }\end{array}$

\section{Governing equations}

Conservation of electrons and ions are expressed as follows.

$$
\begin{gathered}
\nabla \cdot\left(\sigma_{\mathrm{el}}^{\mathrm{eff}} \nabla \phi_{\mathrm{el}}\right)=i_{\mathrm{ct}} \\
\nabla \cdot\left(\sigma_{\mathrm{io}}^{\text {eff }} \nabla \phi_{\mathrm{io}}\right)=-i_{\mathrm{ct}}
\end{gathered}
$$

where $\phi_{\mathrm{el}}$ and $\phi_{\mathrm{el}}$ are the electric potential of the electron-conductive and oxide-ionconductive phase, respectively, and $i_{\text {ct }}$ is the charge-transfer current associated with the electrochemical reaction in the electrodes. Gas diffusion in the porous electrodes is expressed by the dusty-gas model (11).

$$
\begin{gathered}
\nabla \cdot N_{i}=s_{i} \\
\frac{N_{i}}{D_{i, K}^{\text {eff }}}+\sum_{j=1, j \neq i}^{n} \frac{X_{j} N_{i}-X_{i} N_{j}}{D_{i j}^{\text {eff }}}=-\frac{P_{t}}{R T} \nabla X_{i}-\frac{X_{i}}{R T}\left(1+\frac{K P_{t}}{\mu D_{i, K}^{\text {eff }}}\right) \nabla P_{t}
\end{gathered}
$$

where $N_{i}$ and $X_{i}$ are the molar flux and molar fraction, respectively; $S_{i}$ is the source/sink term associated with the electrochemical reaction; $P_{t}$ is the total pressure; $\mu$ is the viscosity; $K$ is the permeability; and $D_{i j}^{\text {eff }}$ and $D_{i, K}^{\text {eff }}$ are the effective molecular and the Knudsen diffusivity, respectively.

The charge-transfer current in the electrodes is expressed by the Butler-Volmer-type equations $(12,13)$.

$$
\begin{aligned}
i_{\mathrm{ct}, \mathrm{cat}} & =i_{0, \mathrm{cat}} l_{\mathrm{TPB}, \mathrm{cat}}\left[\exp \left(\frac{2.0 F}{R T} \eta_{\text {act,cat }}\right)-\exp \left(-\frac{2.0 F}{R T} \eta_{\text {act,cat }}\right)\right] \\
i_{\mathrm{ct}, \text { ano }} & =i_{0, \text { ano }} l_{\mathrm{TPB}, \text { ano }}\left[\exp \left(\frac{2.0 F}{R T} \eta_{\text {act,ano }}\right)-\exp \left(-\frac{F}{R T} \eta_{\text {act,ano }}\right)\right]
\end{aligned}
$$

where $i_{0, \mathrm{TPB}}$ is the exchange current per unit TPB length, and $l_{\text {TPB }}$ is the TPB density. $\eta_{\text {act }}$ is the activation overpotential defined as follows.

$$
\begin{aligned}
\eta_{\text {act,cat }} & =\phi_{\mathrm{io}}-\phi_{\mathrm{el}}-\eta_{\mathrm{con}, \mathrm{cat}} \\
\eta_{\mathrm{act}, \mathrm{ano}} & =\phi_{\mathrm{el}}-\phi_{\mathrm{io}}-\eta_{\mathrm{con}, \mathrm{ano}}
\end{aligned}
$$

where $\eta_{\text {con }}$ is the concentration overpotential defined as follows.

$$
\begin{gathered}
\eta_{\text {con,cat }}=-\frac{1}{4 F} R T \ln \frac{P_{\mathrm{O}_{2}}}{P_{\mathrm{O}_{2}}^{\text {bulk }}} \\
\eta_{\text {con,ano }}=\frac{1}{2 F} R T \ln \left(\frac{P_{\mathrm{H}_{2}}^{\text {bulk }}}{P_{\mathrm{H}_{2}}} \frac{P_{\mathrm{H}_{2} \mathrm{O}}}{P_{\mathrm{H}_{2} \mathrm{O}}^{\text {bulk }}}\right)
\end{gathered}
$$


Empirical formulas were used for the exchange current per unit TPB length. $(14,15)$

$$
\begin{gathered}
i_{0, \text { cat }}=2.14 \times 10^{5} P_{\mathrm{O}_{2}}^{0.376} \exp \left(-\frac{2.43 \times 10^{5}}{R T}\right) \\
i_{0, \text { ano }}=1.30 \times 10^{-3} P_{\mathrm{H}_{2}}^{0.11} P_{\mathrm{H}_{2} \mathrm{O}}^{0.67} \exp \left(-\frac{8.49 \times 10^{4}}{R T}\right)
\end{gathered}
$$

\section{$\underline{\text { Calculation conditions }}$}

The cell temperature was assumed to be constant and uniform in the entire cell and set at $900^{\circ} \mathrm{C}$. Supplied gas was nitrogen-oxygen mixture to the cathode side, and $20 \%$ humidified hydrogen to the anode side. The total pressure on the electrode surfaces was set at $1 \mathrm{~atm}$. Boundary conditions on the electrode surfaces are summarized in TABLE IV. Periodic boundary conditions were set on the side boundaries for all the variables.

TABLE IV. Boundary conditions on the electrode surfaces.

\begin{tabular}{ccc}
\hline & Cathode surface $(\boldsymbol{Z}=\boldsymbol{L})$ & Anode surface $(\boldsymbol{Z}=\mathbf{0})$ \\
\hline $\mathrm{H}_{2}$ partial pressure & - & $P_{\mathrm{H}_{2}}(X, Y, 0)=P_{\mathrm{H}_{2}}^{\text {bulk }}=0.80 P_{\mathrm{t}}$ \\
$\mathrm{H}_{2} \mathrm{O}$ partial pressure & - & $P_{\mathrm{H}_{2} \mathrm{O}}(X, Y, 0)=P_{\mathrm{H}_{2} \mathrm{O}}^{\text {bulk }}=0.20 P_{\mathrm{t}}$ \\
$\mathrm{O}_{2}$ partial pressure & $P_{\mathrm{O}_{2}}(X, Y, L)=P_{\mathrm{H}_{2}}^{\text {bulk }}=0.21 P_{\mathrm{t}}$ & - \\
$\mathrm{N}_{2}$ partial pressure & $P_{\mathrm{N}_{2}}(X, Y, L)=P_{\mathrm{H}_{2}}^{\text {bulk }}=0.79 P_{\mathrm{t}}$ & - \\
Electric potential in Ni/LSM & $\phi_{\mathrm{el}}(X, Y, \mathrm{~L})=V_{\mathrm{t}}$ & $\phi_{\mathrm{el}}(X, Y, 0)=E M F$ \\
Electric potential in YSZ & - & $\frac{\partial \phi_{\mathrm{io}}}{\partial Z}(0)=0$ \\
\hline
\end{tabular}

\section{Results and discussion}

\section{$\underline{\text { Surface Profile }}$}

Figure 3 shows the surface profile of the laser-machined YSZ surface, and also the averaged profile of the repeating unit used for the numerical analysis. The hexagonal pattern was successfully fabricated on the electrolyte surface with the distance between the neighboring craters of $21.85 \mu \mathrm{m}$, the angle formed by $\vec{a}$ and $\vec{b}$ of $59.68^{\circ}$ and the maximum depth of the crater of $23.40 \mu \mathrm{m}$. 

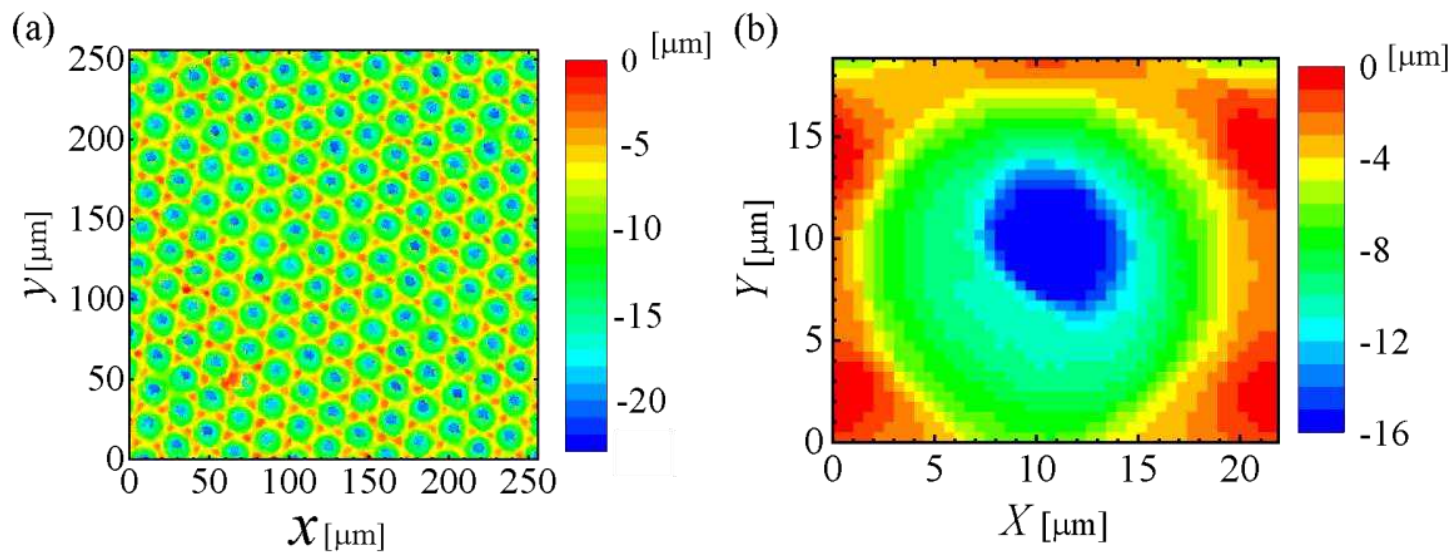

Figure 3. (a) The surface profile of the YSZ surface obtained by the laser profiler. (b) The averaged surface profile of the repeating unit.

\section{$\underline{\text { Numerical Simulation }}$}

Figure 4 shows the current-voltage characteristics of the cells obtained by the experiment and the numerical simulation. The performance of the patterned cell is found to be improved compared with the flat cell in both the experiment and the simulation. Although there is a gap between the experiment and simulation, the performance improvement by the laser-machining is qualitatively reproduced by the numerical simulation.

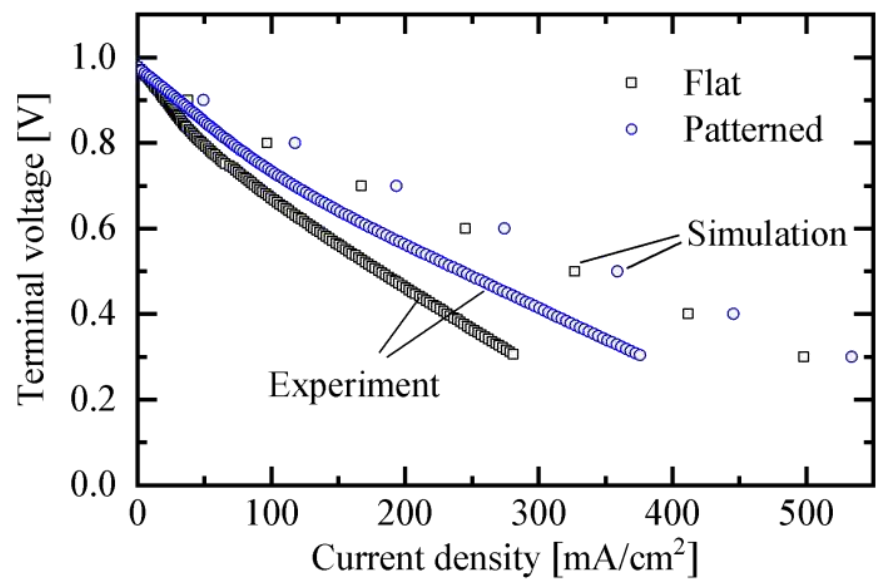

Figure 4. Current-voltage characteristics obtained by the experiment and the numerical simulation at $900^{\circ} \mathrm{C}$ with $20 \%$ humidified hydrogen.

Figure 5 shows the components of the overpotential obtained by the numerical simulation. The ohmic loss associated with the electronic conduction in the electrodes are omitted because they are negligibly small compared with the other overpotentials. Figure 5(a) shows the comparison among the cells with different electrolyte thickness. The effect of the micro-patterns appears on the cathode activation overpotential; it is decreased by ca. $25 \%$ regardless of the electrolyte thickness. Since the cathode thickness is rather thin, the concentration overpotential does not change even if the average cathode thickness is increased by the micro-patterns. The ohmic loss in the electrolyte slightly decreases by the micro-patterns because the average electrolyte thickness is decreased. Figure 5(b) shows 
the comparison among the cells with the different crater depth. As the crater depth increases, the cathode activation overpotential significantly decreases, whereas the other overpotential components remain almost the same.
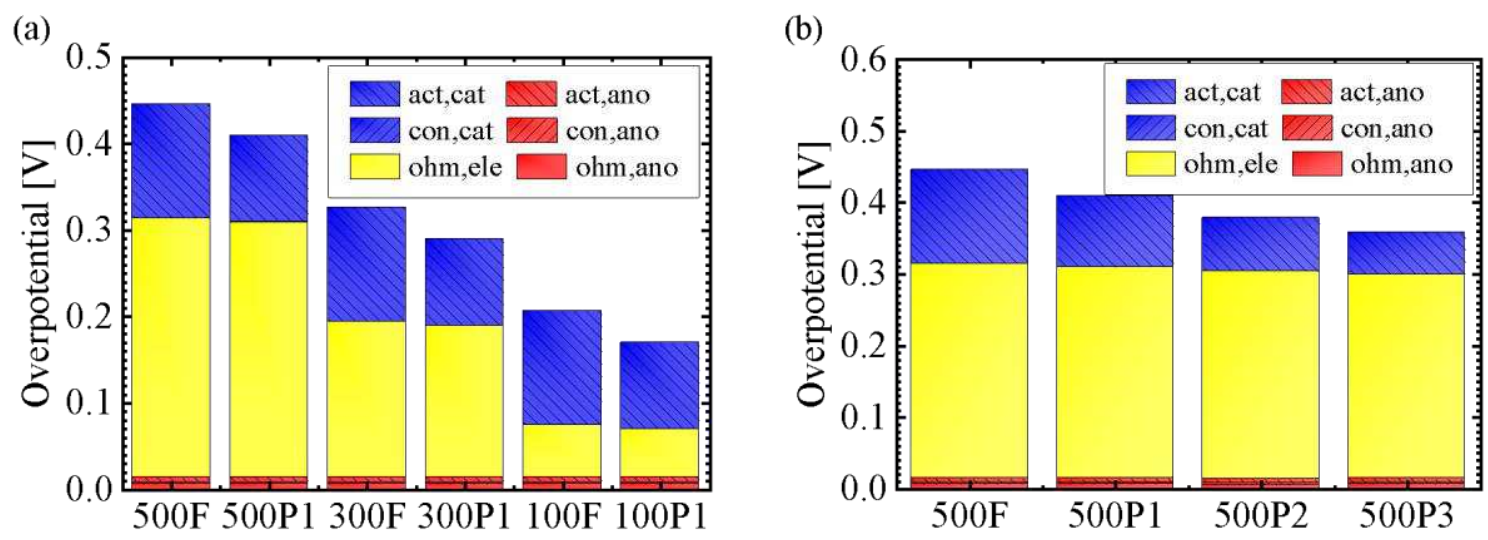

Figure 5. Overpotentials in the cells obtained by the numerical simulation. (a) comparison among the cells with different electrolyte thickness. (b) comparison among the cells with different crater depth.

Figure 6 shows the distribution of the cathode activation overpotential and the chargetransfer current on the cathode-electrolyte interface in the cells with the patterned interface (500P1, 500P2 and 500P3). It is found that the charge-transfer current is concentrated at the bottom of the crater, and the activation overpotential is also higher in the region.

(a) $500 \mathrm{P} 1$
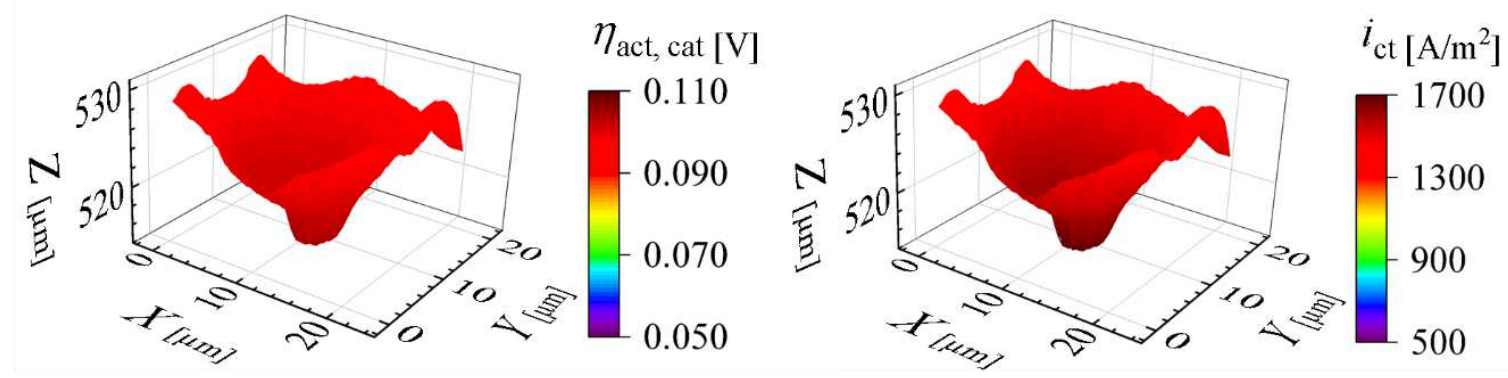

(b) $500 \mathrm{P} 2$
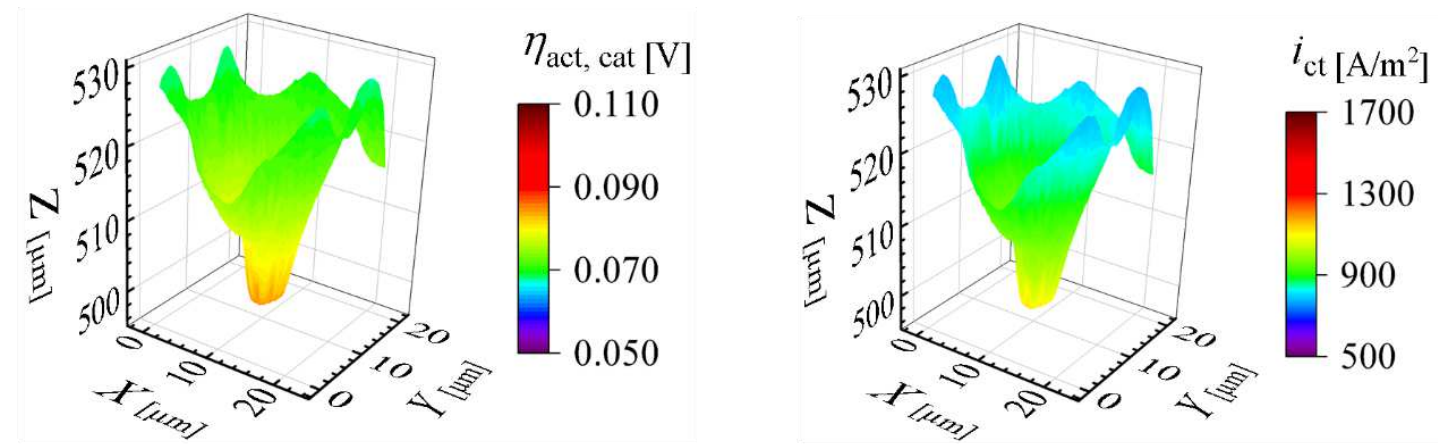

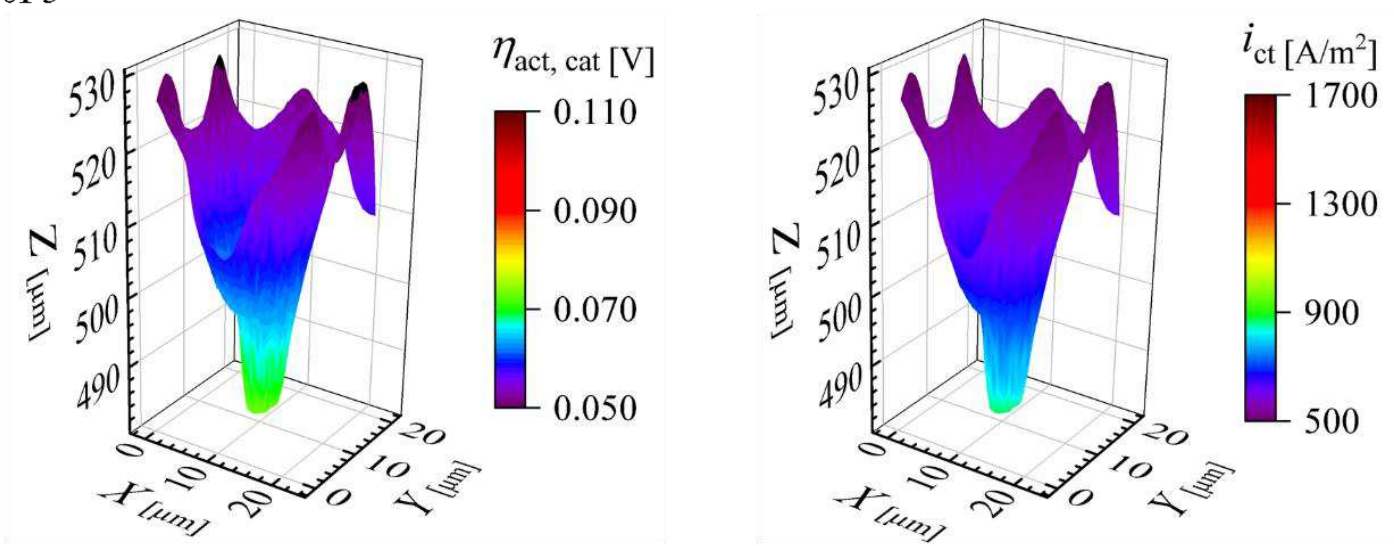

Figure 6. Distributions of the activation overpotential and the charge-transfer current on the cathode-electrolyte interface (a) 500P1, (b) 500P2 and (c) 500P3.

Figure 7 shows the cathode activation overpotential as a function of the interfacial area normalized by the flat interface. It is found that the decrease in the activation overpotential is not proportional to the increase in the interfacial area. Since the simulation was conducted at the constant current density, the local charge-transfer current decreases as the interfacial area increases as shown in the right column of Figure 6 . Also, the local activation overpotential decreases as shown in the left column of Figure 6, which results in the decrease in the total activation overpotential in the cathode. Because of the non-linear characteristics of the relationship between the activation overpotential and the chargetransfer current in eq. (5), the local charge-transfer resistance, $d \eta_{a c t} / d i_{c t}$ increases as the local activation overpotential decreases. This is considered to be the main reason of the non-linear behavior of the cathode overpotential in Figure 7.

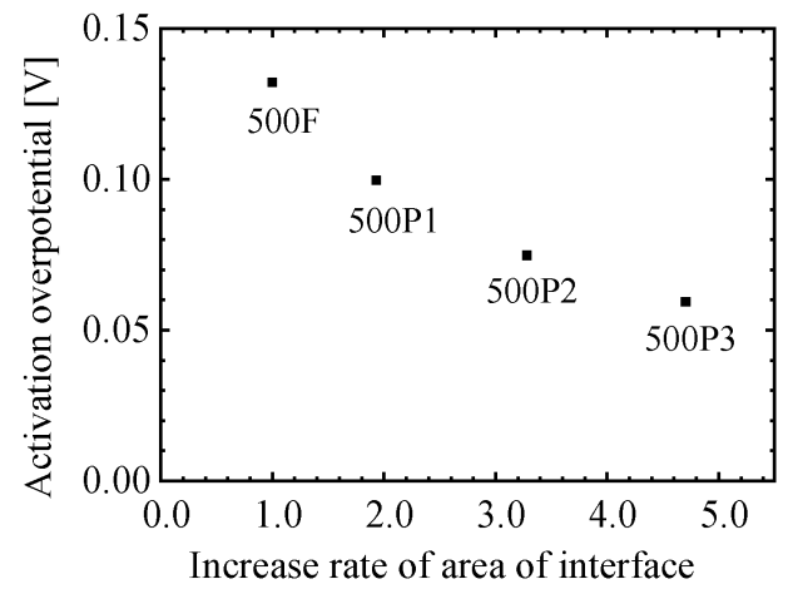

Figure 7. Cathode activation overpotential as a function of the increase ratio of the cathodeelectrolyte interfacial area normalized by the flat interface.

\section{Conclusions}

The pulsed-laser machining was performed on the surface of YSZ flat electrolytes to fabricate micro-patterned craters, increasing the electrode-electrolyte interfacial area. The surface profile of the patterned electrolytes was measured by a laser microscope. Then, 
LSM cathode is fabricated on the laser-machined surface of the YSZ electrolyte, while NiYSZ anode on the flat side. The performance of the fabricated cell with the patterned interface was experimentally evaluated at $900^{\circ} \mathrm{C}$ and compared with that of a conventional cell having the flat interface. 3D numerical simulations were also performed on the patterned cell to understand the distributions of overpotentials and charge-transfer current in the electrodes. A power density enhancement has been confirmed in the cell with the patterned interface in both experiment and simulation.

\section{Acknowledgments}

This work was partially supported by JST under Collaborative Research Based on Adaptable and Seamless Technology Transfer Program through Target-driven R\&D (ASTEP) (No.JPMJTS1613) and by JSPS bilateral open partnership joint research project with Spain, "Optimization of Electrode-Electrolyte Interface of Solid Oxide Fuel Cell by Pulse Laser Ablation and Thin Film Deposition". The characterization of the lasermachined surface was conducted at the Kyoto University Nanotechnology Hub.

\section{References}

1. S. Wang, Y. Jiang, Y. Zhang, J. Yan, W. Li, Solid State Ionics 113-115, 291 (1998).

2. M. Kishimoto, M. Lomberg, E. Ruiz-trejo, N. P. Brandon, Journal of Power Sources 266, 291 (2014).

3. K. Miyawaki, M. Kishimoto, H. Iwai, M. Saito, H. Yoshida, Journal of Power Sources 267, 503 (2014).

4. A. Konno, H. Iwai, K. Inuyama, A. Kuroyanagi, M. Saito, H. Yoshida, K. Kodani, K. Yoshikata, Journal of Power Sources 196 (1), 98 (2011).

5. A. Konno, H. Iwai, M. Saito, H. Yoshida, Journal of Power Sources 196 (18), 7442 (2011).

6. A. Konno, H. Iwai, M Saito, H. Saito, H. Yoshida, Heat Transfer Asian Research, 41, 700 (2012)

7. H. Iwai, A. Kuroyanagi, M Saito, A. Konno, H. Yoshida, T. Yamada, S. Nishiwaki, Journal of Power Sources 196, 3485 (2011).

8. F. Tsumori, Y. Tanaka, Y. Xu, T. Osada, H. Miura, Jpn. J. Applied Physics, 53, 65 (2014)

9. J. A. Cebollero, R. Lahoz, M.A. Laguna-Bercero, A. Larrea, Journal of Power Sources 360, 336 (2017).

10. K. Miyoshi, H. Iwai, M. Kishimoto, M. Saito, H. Yoshida, Journal of Power Sources 326, 331 (2016).

11. D. Arnost, P. Schneider, The Chemical Engineering Journal 57, 91 (1995)

12. S. Nagata, A. Momma, T. Kato, Y. Kasuga, Journal of Power Sources 101 (1), 60 (2001).

13. T. Kawada, N. Sakai, H. Yokokawa, M. Dokiya, M. Mori, T. Iwata, Journal of the Electrochemical Society 137 (10), 3042 (1990)

14. K. Miyoshi, T. Miyamae, H. Iwai, M. Saito, M. Kishimoto, H. Yoshida, ECS Transactions 68 (1), 657 (2015)

15. D. Kanno, N. Shikazono, N. Takagi, K. Matsuzaki, N. Kasagi, Electrochimica Acta 56 (11), 4015 (2011) 